\title{
THE DUTCH ELM DISEASE
}

By Curtis May, Associate Pathologist, Department of Botany, Ohio Agricultural Experiment Station, and G. F. GRavaTT, Senior Pathologist, Division of Forest Pathology, Bureau of Plant Industry, United States Department of Agriculture

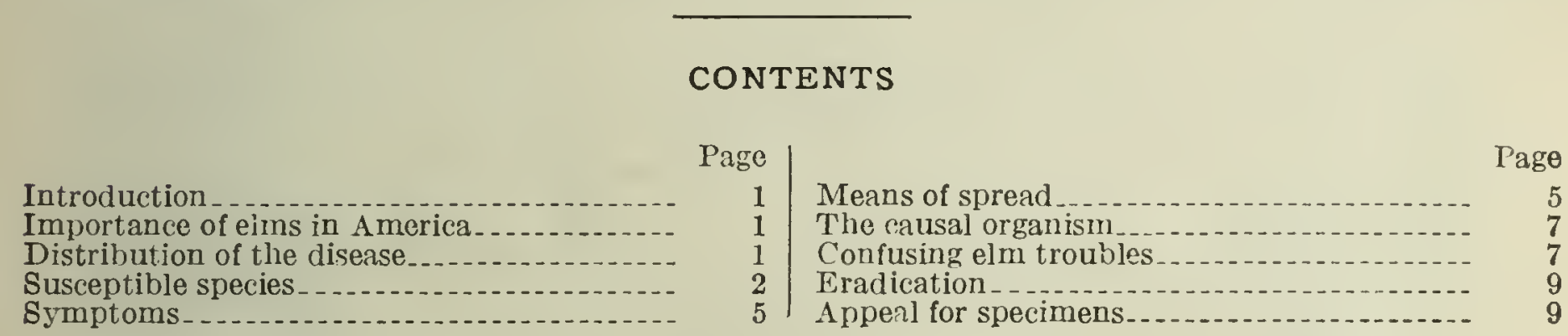

\section{INTRODUCTION}

The Dutch elm disease, caused by the fungus Graphium ulmi Schwarz, was discovered in the United States for the first time during the summer of 1930 . Its presence seriously threatens the future of one of our valuable shade and forest trees. The purpose of this circular is to interest shade-tree owners, nurserymen, tree surgeons, foresters, and others working with trees in sending in specimens from unhealthy elms so that the distribution of the disease may be ascertained at once as a basis for control policies.

\section{IMPORTANCE OF ELMS IN AMERICA}

The American elm (Ulmus americana L.) is one of our most important shade and ornamental species. It is extensively planted in this country from coast to coast and from Canada to Mexico. In New England this tree gives a distinctive character to the streets and parks. Other species of elms are used also as ornamentals in various parts of the country.

In forests elms are important in mixed hardwood stands from the Great Plains area to the Atlantic Ocean. The six States leading in the production of elm lumber are Wisconsin, Michigan, Indiana, 'Tennessee, Arkansas, and Louisiana.

\section{DISTRIBUTION OF THE DISEASE}

The Dutch elm disease, which was first noticed in the Netherlands in 1919, has caused the destruction of many elms in that country. There is as yet no indication of any decrease in its virulence. It quickly spread to Belgium, Germany, and France, where in many localities it is likewise causing widesprear death of elms. (Fig. 1.) In Great Britain the first case was found in 1927, and now the dis-

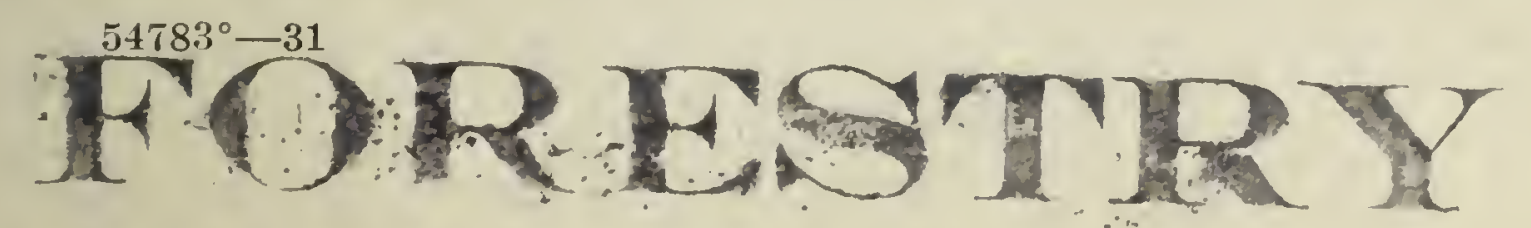


ease is reported as prevalent in the southern part of the island. It has already spread into Norway, with a cool climate, and into northern Italy, with a warm climate, which indicates that the disease flourishes under widely different conditions of temperature.

In the summer of 1930 this disease was identified as present in America independently by Christine Buisman, a Dutch plant pathologist then traveling here, and the senior writer. Three infected trees were found in different parts of Cleveland (fig. 2) and one in Cincinnati, Ohio. None of the infected trees came from nurseries, and there is at present no satisfactory explanation for the presence of the disease in these two localities.

The native home of the causal fungus is not known. The disease is called the Dutch elm disease because it was first noticed in the

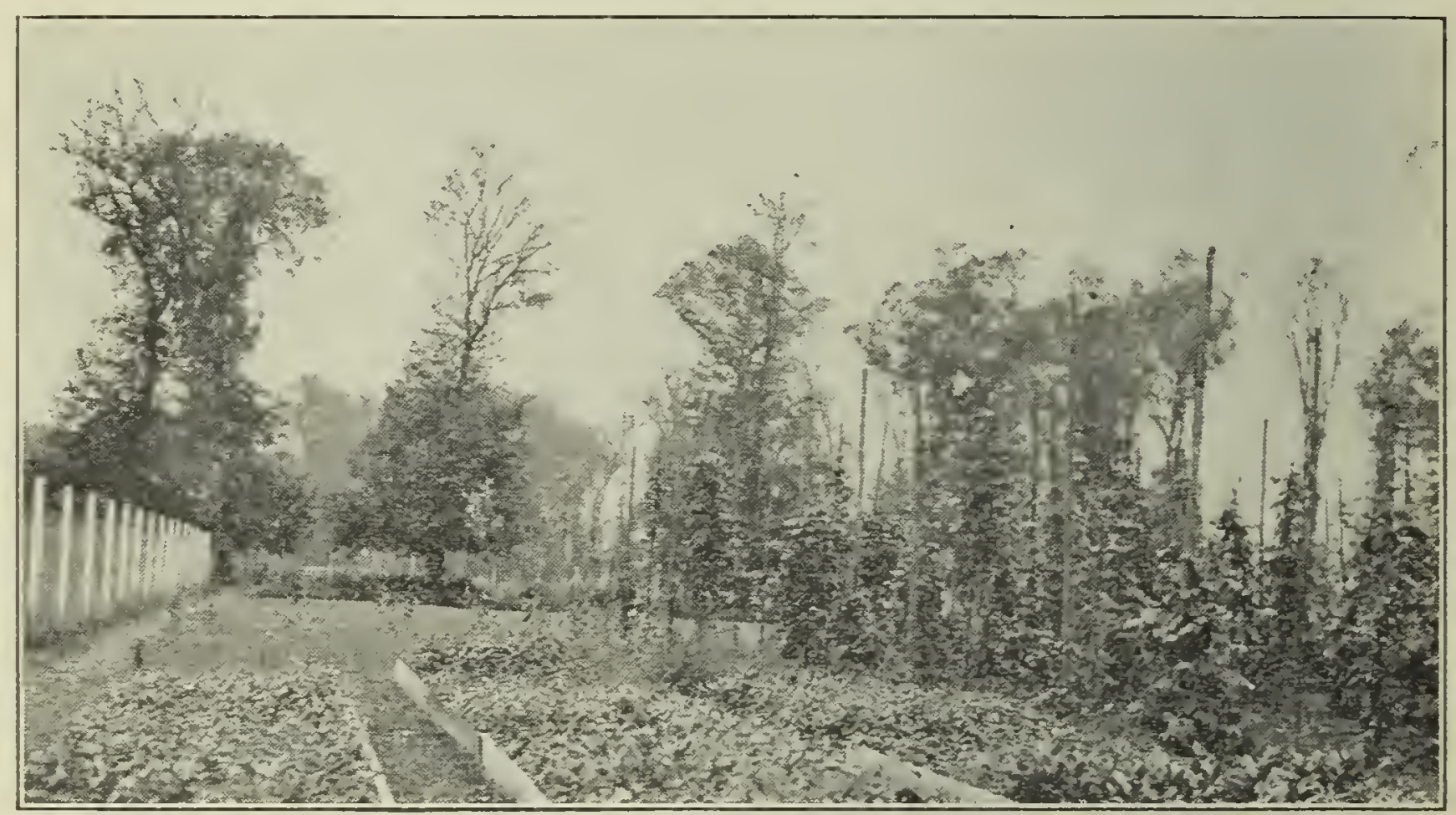

Figure 1.-Large elm trees at Versailles. France, in rilrious stages of dying from the Dutch elm disease in July, 1930. (Photograph b: R. Kent Beattie)

Netherlands, whence it spread to other European countries. It is possible that the fungus may be a native of Asia, or eren of North America. However, this latter source seems highly improbable. The American elm is markedly susceptible to the disease, and, although for a number of years plant pathologists and tree workers in the United States have known of its seriousness in Europe and have been watching for it here, thus far only the abore-mentioned four affected trees have been discovered.

\section{SUSCEPTIBLE SPECIES}

The Dutch elm disease is most prevalent on trees 15 to 40 years old, but in Europe both nursery seedlings and large mature trees have been found infected. In Europe nearly all species and varieties of elm that are grown extensively and that have been exposed to the disease appear to be susceptible. The considerable variation reported in the susceptibility of individual trees or strains within a species may account for some differences of opinion regarding the relative susceptibility of certain species and varieties. 


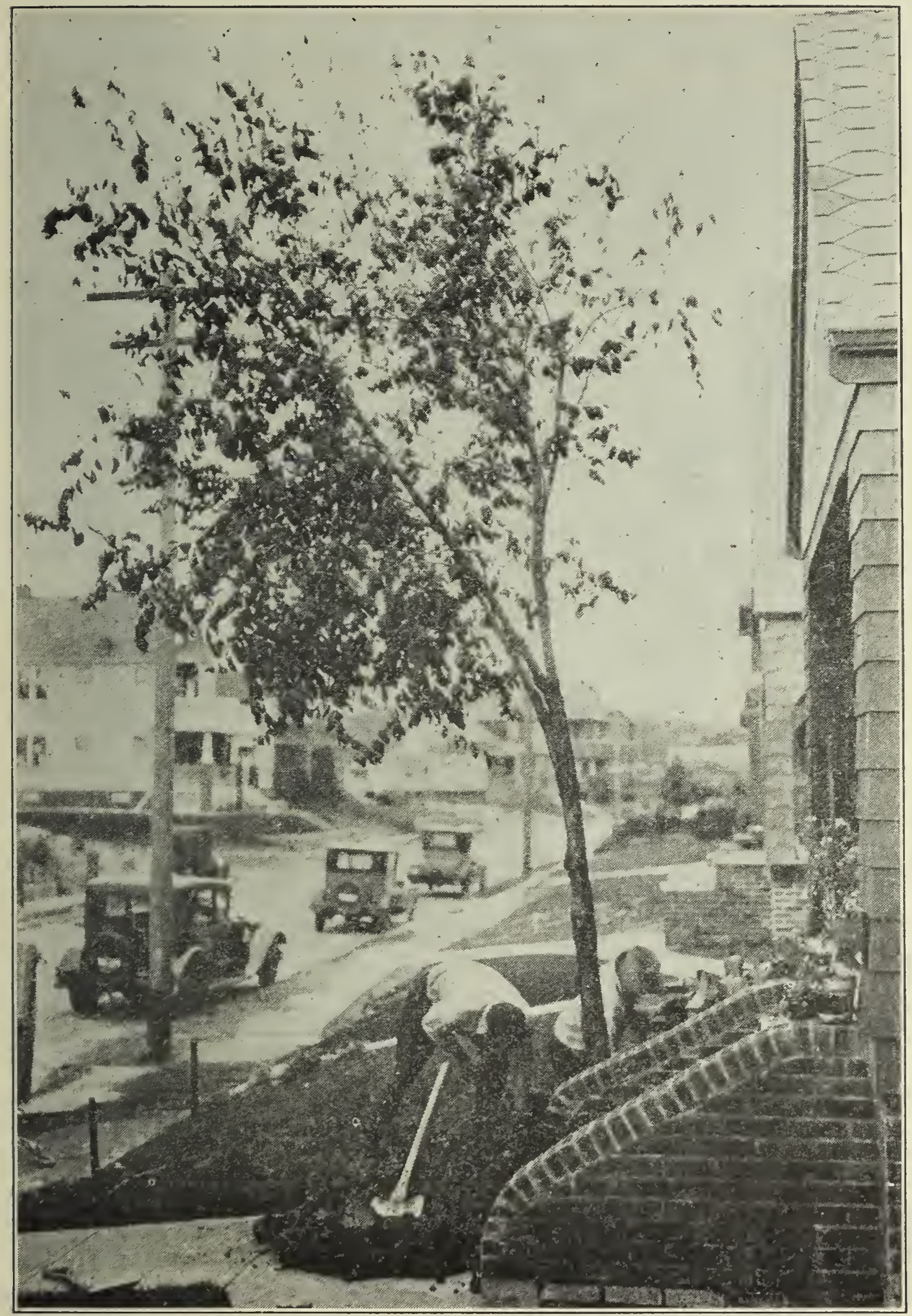

Figure 2,-One of the wilted American elms which was attacked by the Dutch elm-disease fungus in Cleveland, Ohio. The tree filst showed wilted parts in May, according to the report of the owner; and by the middle of July, when it was removed and burned, most of the tree had wilted, and many of the leaves har aropped. 'The tree had discolored streaks in the roots as well as in the trunk and twigs 
The American elm, which is of most interest in this country, has been found to be severely attacked in both England and Germany. Inoculations on young trees, made by the senior writer under quarantine conditions, as well as those of European investigators, confirm its high susceptibility. (Fig. 3.)

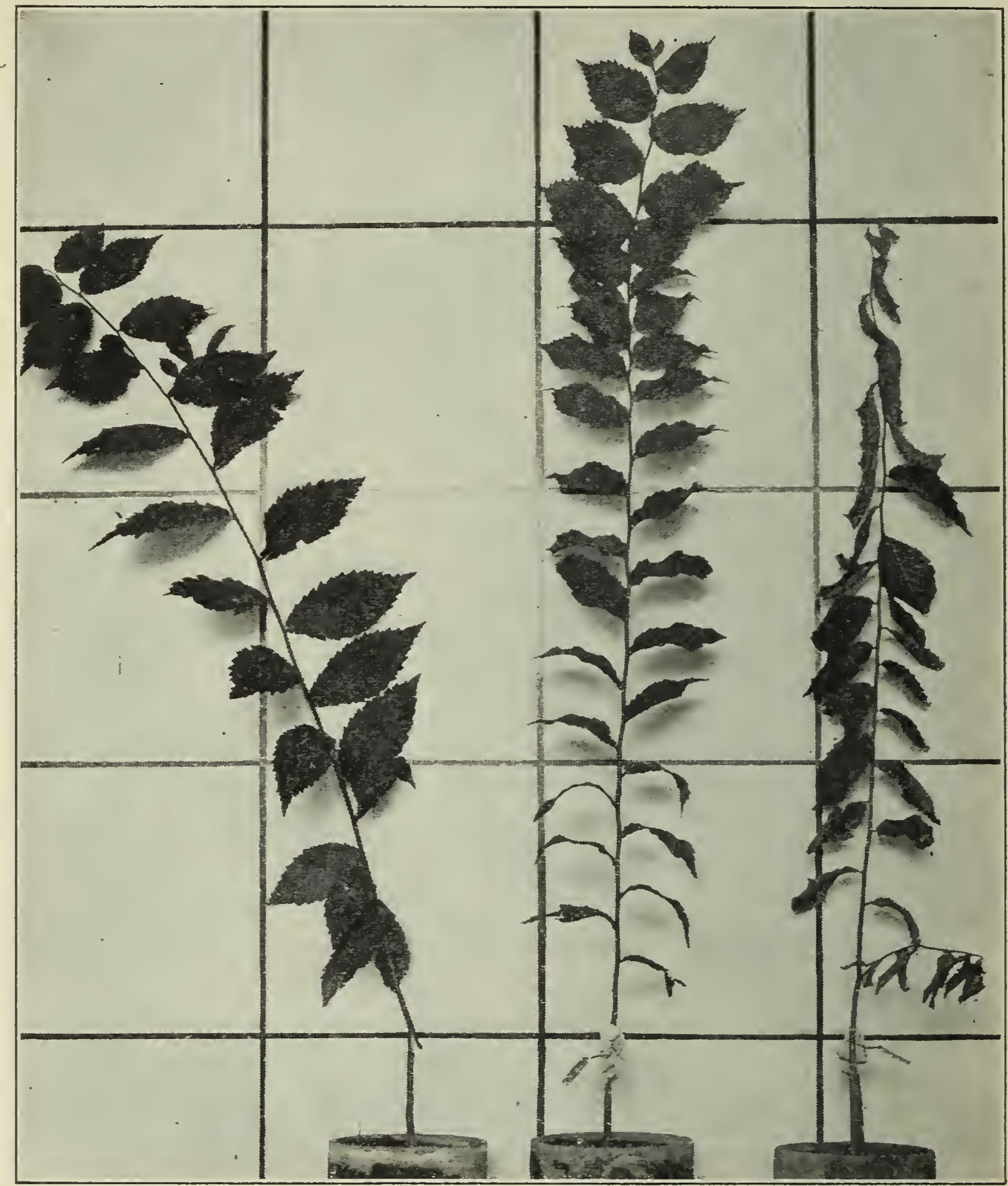

Fratre 3.-On the right is a roung American elm 14 days after it was inoculated with the Dutch elm-disease fungus. The seedling in the center is one of the check trees. Which were treated similarly except that the fungus was not inserted in the wound. The check tree on the left was almost completely serered, but it showed no signs of wilting

The English elm (Ulmus campestris), the Holland elm ( $C$. hollandica), and the Scotch elm (U. glabra), which are planted to some extent as ornamentals in this country, are likewise susceptible to the disease. Zelkova keaki, a tree closely related to the elms, also has been found by inoculation to be susceptible. 


\section{SYMPTOMS}

Usually the first symptom of the Dutch elm disease is the sudden wilting of the leaves of a part of the crown of the tree, of the entire tree, or of the tips of some of the side branches. Drying of the leaves and defoliation of the affected parts may follow. The wilted leaves often turn yellow or brown before falling, and the affected parts stand out in color contrast with the rest of the tree. At times the wilted leaves remain green and crisp and cling to the twigs. The one or two end leaves frequently persist longer than the others, and the tips of the twigs bend, giving a characteristic appearance, which may be of value in detecting affected trees in winter. At Cleveland wilting appeared on all three of the trees in the latter part of May, but in England the trouble rarely is evident until June and frequently not until July or August. The progress of the disease on individual trees varies. One limb may wilt one year and others in succeeding years, or the whole tree may die in a single season. In all three of the cases in Cleveland the first wilting was followed in the same season by that of additional parts of the trees.

On some affected trees the twig growth is short, the leaves fail to reach normal size, and the foliage is thin. Often infected trees produce numerous suckers along the trunk and at the bases of the large branches. These new shoots may turn brown, or the leaves may remain green throughout the season. Suckering, however, is not a specific symptom confined to the Dutch elm disease. Trees affected with this disease may die at the end of the first season or may persist for some years.

If a clean cut is made across a twig affected with the Dutch elm disease, a brownish discoloration will be seen in the sapwood. (Figs. $\frac{1}{x}$ and 5 .) In general the discolored tissue does not form a completely closed circle but is made up rather of numerous small brown dots. Sometimes, however, a continuous ring is formed. The discoloration may appear in one or more annual rings. If the bark is peeled away and the sapwood exposed, the discoloration is evident as a series of short, brown streaks. A single streak does not extend for a long distance down the twig. In late summer it is sometimes necessary to cut away some of the summer wood to find the short stippled streaks in the spring wood.

\section{MEANS OF SPREAD}

Our knowledge of this disease is as yet based primarily on European publications. Investigators there have found that elm trees readily become infected with the fungus through wounds on buds, twigs, limbs, trunks, or roots. Natural infections usually take place in the upper portion of the tree. Since the fungus grows principally in the sapwood, which is usually inclosed by a layer of healthy bark, outside spore production is supposed to be very slight until after the tree or some part of it is killed. Even then spore production on the outer surface is uncommon when compared, for instance, with the enormous spore production of the fungus causing the chestnut blight. Tinder very farorable conditions spores may be produced on cut surfaces of the tree. stumps, chips, twigs, and in insect tunnels in the wood. Spores are probably produced in 
insect tunnels much more frequently than on exterior surfaces. The fungus has been found in leafstalks, but as yet no information is available as to the importance of leaves in the dissemination of the disease.

In Europe the spread of the disease from tree to tree is now considered to be primarily by means of an elm-bark beetle (Scolytus scolytus Fabr.) which carries the fungus on its body and which makes wounds in different parts of the tree, thus giving the fungus a chance to secure entrance. This particular elm beetle has not been found in America, but it is feared that some of our native

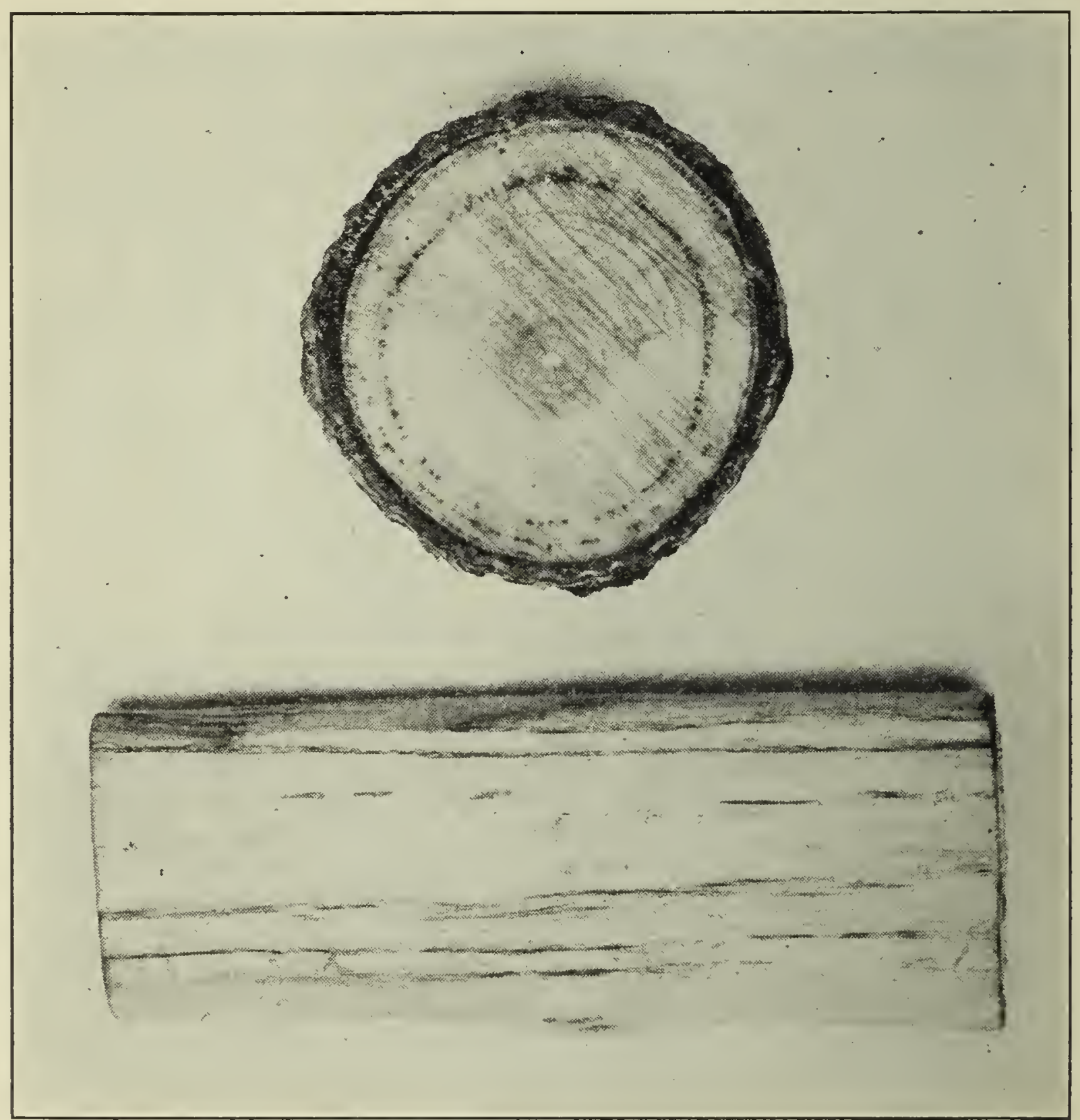

FIGURE 4.- Sections from a diseased limb, showing the discolored areas or streaks in the sapwood

elm insects may prove to be carriers, because in Europe the spores have been found on the bodies of insects other than this bark beetle.

Although the Dutch elm disease is not prevalent in nurseries in Europe, it is known to occur in them at times. Therefore, nursery stock is a possible means of spread, especially for long distances. Since June 1, 1919, the importation of elm nursery stock into the United States has been under special permit only and has been limited to such material as is necessary for the purpose of keeping the country supplied with new varieties and necessary propagating stock or for any necessary experimental, educational, or scientific 
purpose; and since the seriousness of the Dutch elm disease in Europe has been realized, no such permits even have been issued. No imported elms have been known to come to the Ohio region from Europe since the disease was discovered in the Netherlands.

\section{THE CAUSAL ORGANISM}

Graphium ulmi, the fungus causing the Dutch elm disease, is closely related to some of the organisms that produce blue stains in the wood of pine, gum, and other trees. In from three to seven days the fungus grows out from small pieces of diseased sapwood planted in potato-dextrose agar. The growth generally has a slimy appearance. In the writers' cultures concentric zones were formed in all the original isolations; but after the fungus had been in culture for some time a greater amount of aerial mycelium developed in the subcultures, and the zonation became indistinct.

Young cultures form spores acrogenously and in great abundance. The numerous glistening spore heads or clumps of various sizes show up very clearly under the low power of the microscope. In the writers' cultures the spores range from 3 by 1.5 microns to 7 by 4 microns. The spores are generally more or less pear shaped, but also vary considerably in this respect. Yeastlike budding of the spores is commonly found in the cultures, and on some media the culture itself looks like a yeast colony.

The Cephalosporiumlike stage of the fungus usually is followed in a few days by the coremial stage. The coremium is a spore-bearing structure made up of a black stalk, lighter colored at the top, and surmounted by a subspherical ball of spores. These spores are hyaline and average about 3.2 by 1.7 microns. The stalks may be up to 1,200 microns long by 120 microns thick.

These coremia grow up both from the bits of diseased wood used for the isolations and from the agar itself. The production of coremia by the fungus is somewhat erratic, and most of the writers' subcultures are no longer producing this stage.

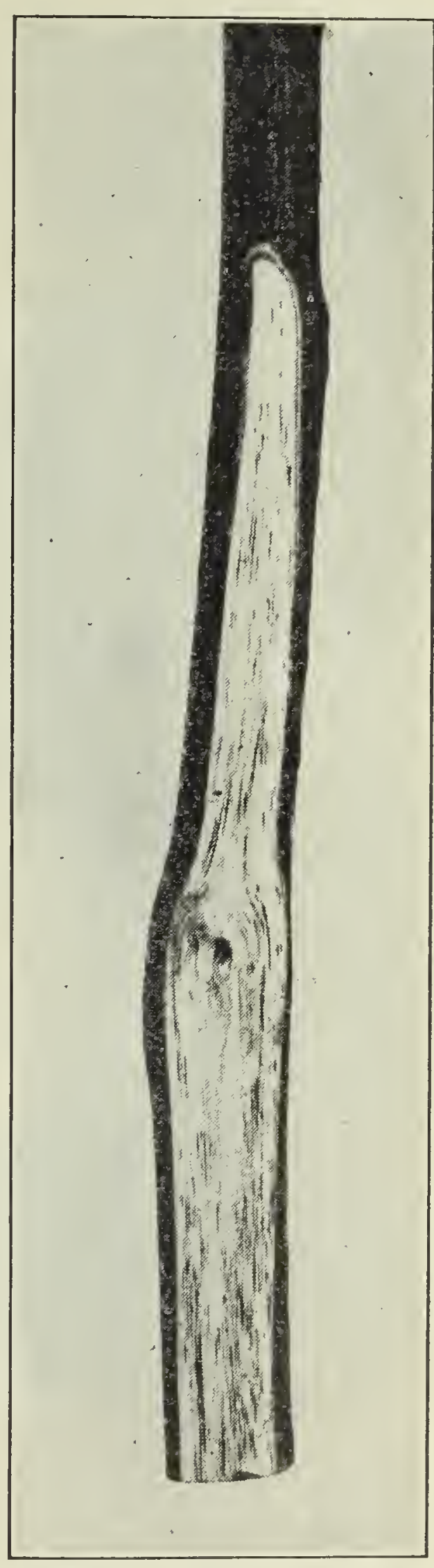

Figure 5.-Portion of a diseased elm with most of the bark removed to show the short dark streaks in the sal pwood

\section{CONFUSING ELM TROUBLES}

At present it is often impossible to state from a field examination whether a wilted elm has or has not the Dutch ehm disease. Even the presence of the characteristic streaks in the sapwood does not make field diagnosis positive, since some other fungi and bacteria 
cause similar types of wood discoloration. Most of the organisms cultured from discolored sapwood are regarded as weak parasites; that is, organisms that are making growth in the living sapwood only because the tree has been weakened. Trees injured by soil fillings, drought, illuminating gas, insects, etc., are invaded by fungi which help to hasten the death of some part or the whole of the tree. Graphium also invades weakened trees, but in Europe it differs from parasites of low virulence in being able by itself to bring about the death of vigorously growing trees.

Except by laboratory cultures, it is usually impossible to distinguish elms attacked by the fungus causing the Dutch elm dis-

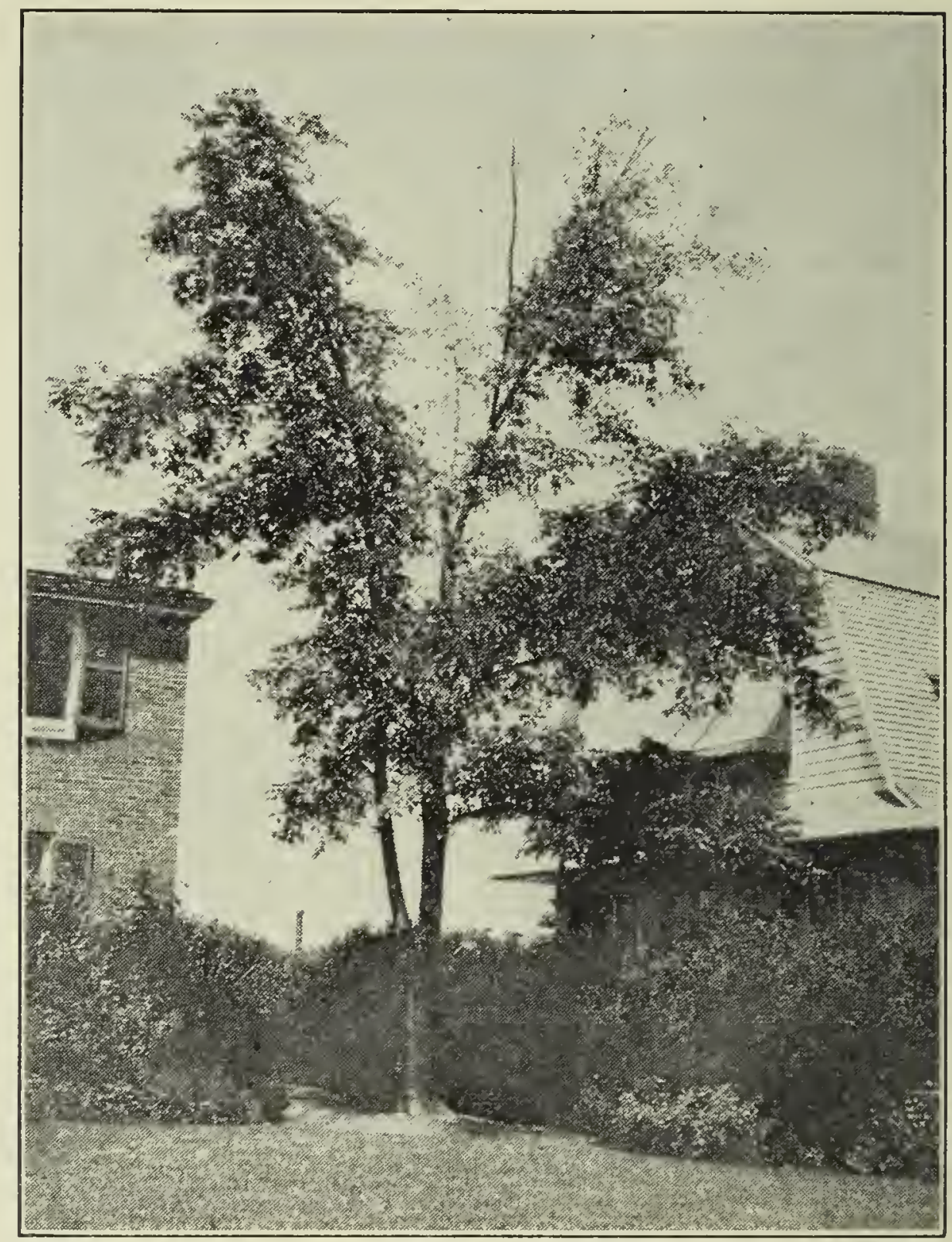

Figure 6.-An American elm attacked by Verticillium. The gross symptoms are very similar to those of the
Dutch elm discase

ease from those attacked by the fungus group Verticillium (fig. 6), which causes the wilt of maples and a number of other trees and shrubs and many herbaceous plants and which is an active parasite growing in the living sapwood of the tree. As many of the external symptoms of the two diseases are similar and as only a few trees affected by them in this country have been studied, it is inadvisable to attempt to distinguish them in the field. However, the discoloration of the sapwood is somewhat more continuous with the Verticillium wilt than with the Dutch elm disease. In the Verticillium wilt of small nursery trees of maple and elm, and in some of the large planted trees, the disease starts in the roots and grows upward. 
In the Dutch elm disease infection through the root under natural conditions has never been reported. In one case in Cleveland, cultures showed that Graphium and Verticillium were both present in the same tree.

The twig blight of the elm, caused by the fungus Sphaeropsis ulmicola, is widely distributed in this country. Individual twigs or many twigs over a tree may be killed by it, and the continuation of the attack often results in the death of the tree. This disease seems to be more serious under Wisconsin climatic conditions than under those of the Eastern States. Affected twigs usually show definitely cankered and killed areas in the bark, accompanied by short, continuous, darkened areas in the wood. On the other hand, a recently wilted branch or twig from a tree affected only by Graphium or Verticillium will have normal green bark without cankers and numerous discolored streaks in the sapwood.

For a number of years there has been an extensive dying of the t.lms in parts of the Ohio and upper Mississippi River Valleys. The underlying cause of this dying is not known, though various fungi of a parasitic nature have been found on the affected trees. The external symptoms in some cases resemble those of the Dutch elm disease, but in most cases the streaks and spotting in the sapwood characteristic of that disease are absent.

\section{ERADICATION}

No cure is known for a tree affected with the Dutch elm disease unless the infection is entirely localized in a branch that can be completely removed. Since apparently the disease is as yet in an incipient state in the United States, the only logical program involves the location and the eradication of all infected trees. In Europe the disease is widespread and such eradication would not be feasible. Data on many phases of this disease are still lacking, but enough is known to justify aggressive action at the present time. Delayed action may result in the loss of the opportunity to eradicate the disease from this country.

To eradicate a tree affected with the Dutch elm disease, remove and burn all parts except the deeper roots. Those roots remaining should be covered with 6 inches or more of soil. Burn all chips and pieces of bark. Pick up and burn the leaves. Treat the tools used with denatured alcohol or some other active disinfectant.

\section{APPEAL FOR SPECIMENS}

Available Government funds are merely sufficient to do the necessary cultural work on specimens, to make some research studies, and to conduct inspection around known infections. State pathologists, foresters, and State departments of agriculture in the important States are fully alive to the danger from this disease and are cooperating in the survey now being made. But the cooperation of tree workers and owners in locating and sending in twig and branch specimens from elm trees suspected of being infected with the Dutch elm disease is also necessary. 'The territory over which the elm grows is so extensive that the only possible way of securing an estimate of present conditions is through widespread cooperation. 
The best specimens for laboratory culture work are twigs and small branches from one-quarter to 1 inch in diameter and from 5 to 10 inches in length. They should be taken preferably from a part of the tree that has recently wilted or died or that has small, undersized leaves, rather than from parts that have been dead for many months. Several such pieces should be securely wrapped in paper and mailed to the Dutch Elm Disease Laboratory, Agricultural Experiment Station, Wooster, Ohio, or to your State plant pathologist, together with a letter giving the location of the tree and its symptoms. The package should bear the name of the sender, and if specimens are from more than one tree, each should be numbered or otherwise designated. The specimens will be cultured and the cause of the disease determined at the Dutch Elm Disease Laboratory, which is cooperatively maintained by the Bureau of Plant Industry and the Ohio Agricultural Experiment Station. This laboratory will receive material from all parts of the United States and is not limited to that from Ohio. Information regarding the results of the cultures will be sent to each collector.

While at the present time it is perhaps more probable that the Dutch elm disease may be found in ornamental rather than in forest trees, still the cooperation of foresters in the search for it is earnestly requested. This disease has spread to the forests in Europe, and the elm forests of this country must be watched. In addition to diseased twigs, pieces of stained elm logs and lumber are desired. 


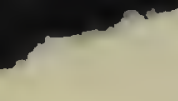


